\title{
PROPERTIES OF LOW RESIDUAL STRESS SILICON OXYNITRIDES USED AS A SACRIFICIAL LAYER
}

\author{
S. Habermehl, A. K. Glenzinski, W. M. Halliburton and J. J. Sniegowski \\ Sandia National Laboratories, Albuquerque, NM 87185, sdhaber@sandia.gov
}

\begin{abstract}
Low residual stress silicon oxynitride thin films are investigated for use as a replacement for silicon dioxide $\left(\mathrm{SiO}_{2}\right)$ as sacrificial layer in surface micromachined microelectrical-mechanical systems (MEMS). It is observed that the level of residual stress in oxynitrides is a function of the nitrogen content in the film. MEMS film stacks are prepared using both $\mathrm{SiO}_{2}$ and oxynitride sacrificial layers. Wafer bow measurements indicate that wafers processed with oxynitride release layers are significantly flatter. Polycrystalline Si (poly-Si) cantilevers fabricated under the same conditions are observed to be flatter when processed with oxynitride rather than $\mathrm{SiO}_{2}$ sacrificial layers. These results are attributed to the lower post-processing residual stress of oxynitride compared to $\mathrm{SiO}_{2}$ and reduced thermal mismatch to poly-Si.
\end{abstract}

\section{INTRODUCTION}

For microelectromechanical systems based on polysilicon surface micromachining, silicon dioxide deposited from tetraethoxysilane (TEOS) is commonly used as an etch release layer between mechanical components [1]. For the relief of mechanical stress in poly-Si components, high temperature anneals $(>1000 \mathrm{C}$ ) are very effective [2]. Unfortunately, this temperature cycling does not stress relieve the $\mathrm{SiO}_{2}$ layers, and in practice it drives the oxide into a high state of compressive residual stress $(\sim-250 \mathrm{MPa})$. This level of residual stress can lead to excessive wafer bow that introduces wafer handling problems and ultimately film or wafer failure. Low stress silicon oxynitride films, as a substitute for silicon dioxide, are investigated to address the issue of stress.

Silicon oxynitrides $\left(\mathrm{SiO}_{\mathrm{x}} \mathrm{N}_{\mathrm{y}}\right)$ exhibit a number of unique electronic and optical properties found to be useful in applications such as CMOS gate dielectrics and nonvolatile memories [35]. By varying the nitrogen content, thermally stable films with very low residual stress can be deposited [6].

In this paper a process for depositing low residual stress oxynitrides is identified. The flatness of wafers processed with a standard MEMS film stack are compared for stacks processed with TEOS $\mathrm{SiO}_{2}$ and oxynitride sacrificial layers. The process induced wafer bow is measured and compared to theoretical predictions. Additionally, results are reported on the flatness of released and dried poly-Si cantilevers which were processed with $\mathrm{TEOS}^{\mathrm{SiO}}{ }_{2}$ and oxynitride sacrificial layers.

\section{EXPERIMENT}

Patterned after the SUMMiT process [7], film stacks are deposited on $150 \mathrm{~mm} \mathrm{Si(100)}$ wafers, $675 \mu \mathrm{m}$ thick. The foundation consists of a $0.3 \mu \mathrm{m}$ poly-Si film deposited over a $0.8 \mu \mathrm{m}$ Si-rich, low stress nitride [8], which is deposited over a $0.6 \mu \mathrm{m}$ thermal $\mathrm{SiO}_{2}$ layer. Deposited upon this foundation is a $2.0 \mu \mathrm{m}$ sacrificial oxide, followed by a $2.25 \mu \mathrm{m}$ mechanical poly-Si layer capped with a $0.5 \mu \mathrm{m}$ sacrificial oxide. In these experiments wafer bow is compared for film stacks prepared with oxynitride versus oxide sacrificial layers. Oxynitride films are 


\section{DISCLAIMER}

This report was prepared as an account of work sponsored by an agency of the United States Government. Neither the United States Government nor any agency thereof, nor any of their employees, make any warranty, express or implied, or assumes any legal liability or responsibility for the accuracy, completeness, or usefulness of any information, apparatus, product, or process disclosed, or represents that its use would not infringe privately owned rights. Reference herein to any specific commercial product, process, or service by trade name, trademark, manufacturer, or otherwise does not necessarily constitute or imply its endorsement, recommendation, or favoring by the United States Government or any agency thereof. The views and opinions of authors expressed herein do not necessarily state or reflect those of the United States Government or any agency thereof. 


\section{DISCLAIMER}

Portions of this document may be illegible in electronic image products. Images are produced from the best available original document. 
deposited by low pressure chemical vapor deposition (LPCVD) at $900 \mathrm{C}$ in a mixture of dichlorosilane, ammonia and nitrous oxide.

Wafer bow, warp and radius of curvature are measured using a Tencor model FLX-2320 thin film stress monitor to determine the effect of the different sacrificial oxides upon process induced wafer warpage. The maximum wafer bow is reported, in lieu of wafer warp, to allow for differentiating between convex and concave deformation [9].

Interferometry is utilized to determine the deflection of $20 \mu \mathrm{m} \times 475 \mu \mathrm{m}$ poly-Si cantilevers fabricated with either the $\mathrm{SiO}_{2}$ or oxynitride sacrificial layers [10].

\section{RESULTS AND DISCUSSION}

The residual film stress of continuous LPCVD poly-Si and TEOS $\mathrm{SiO}_{2}$ films under post deposition $\mathrm{N}_{2}$ anneal is shown in Fig. 1. It has been reported that in order to achieve stress relief to less than $10 \mathrm{MPa}$ in released poly-Si MEMS structures it is necessary to anneal the film to a minimum of $1000 \mathrm{C}$ for an extended period [2]. Under these conditions the LPCVD TEOS film, though deposited with a low level of residual stress, is observed to undergo a transition to a high state of compressive stress. For processes that deposit films on both sides of the wafer the stress forces balance and the wafer will not deform. However, for processes that deposit films on one side only the compressive stress in the TEOS oxide can lead to significant wafer deformation. Even if double-sided deposition techniques are utilized photolithographic patterning and etching of the wafer will create discontinuous films on the front side leading to an imbalance in the stress forces and possible wafer deformation.

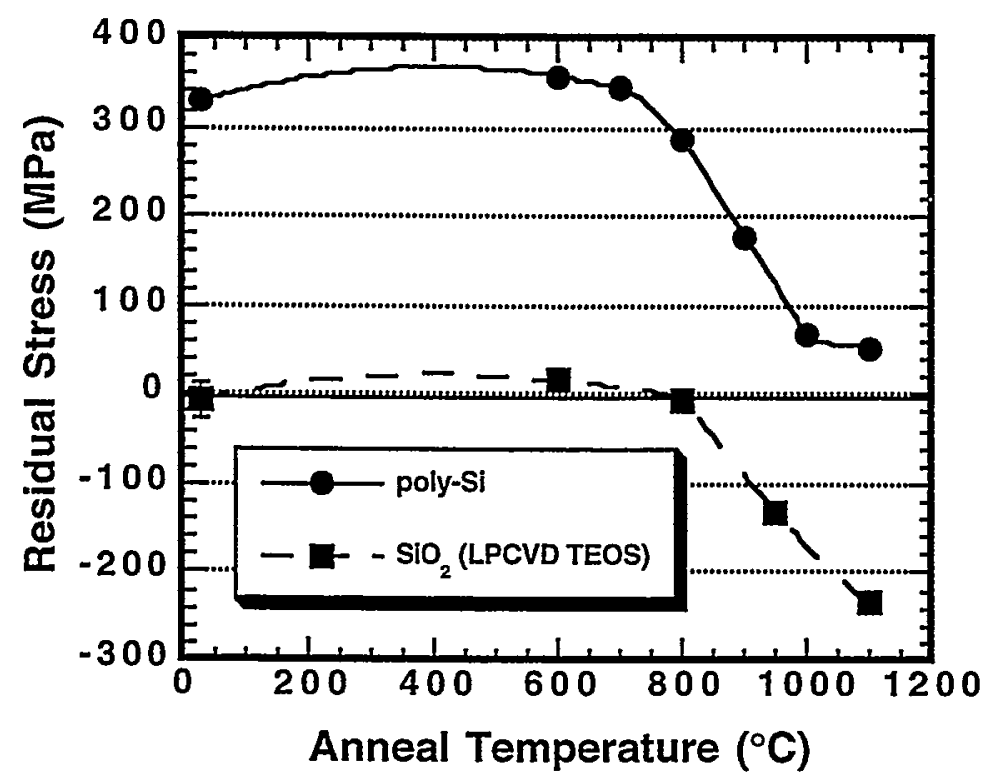

Figure 1. Post anneal residual stress for $2.0 \mu \mathrm{m}$ poly-Si and $\mathrm{TEOS} \mathrm{SiO}_{2}$ films. Anneal time is 3 $h$, in $\mathrm{N}_{2}$.

Figure 2 depicts the predicted wafer deformation for the film stack as each layer is grown or deposited and, at the end, annealed for 3 hours at $1100 \mathrm{C}$. The maximum wafer bow is determined from the predicted radius of curvature for each film stack, which is calculated using 
Stoney's equation [11]. It is assumed that there is no film on the wafer back side and the wafers are initially flat. It is also assumed that the residual stress of a given film stack is given by a thickness weighted linear combination of the individual films' residual stress; this assumption has been experimentally validated [12]. For a film stack with $\mathrm{TEOS} \mathrm{SiO}_{2}$ sacrificial layers the wafer bow is expected to be dominated by the high residual tension of the poly-Si layers. Upon stress relieving the poly-Si via high temperature anneal, residual compression in the oxide layers dominate and the wafer bow reverses (from $-120 \mu \mathrm{m}$ to $+95 \mu \mathrm{m}$ ).

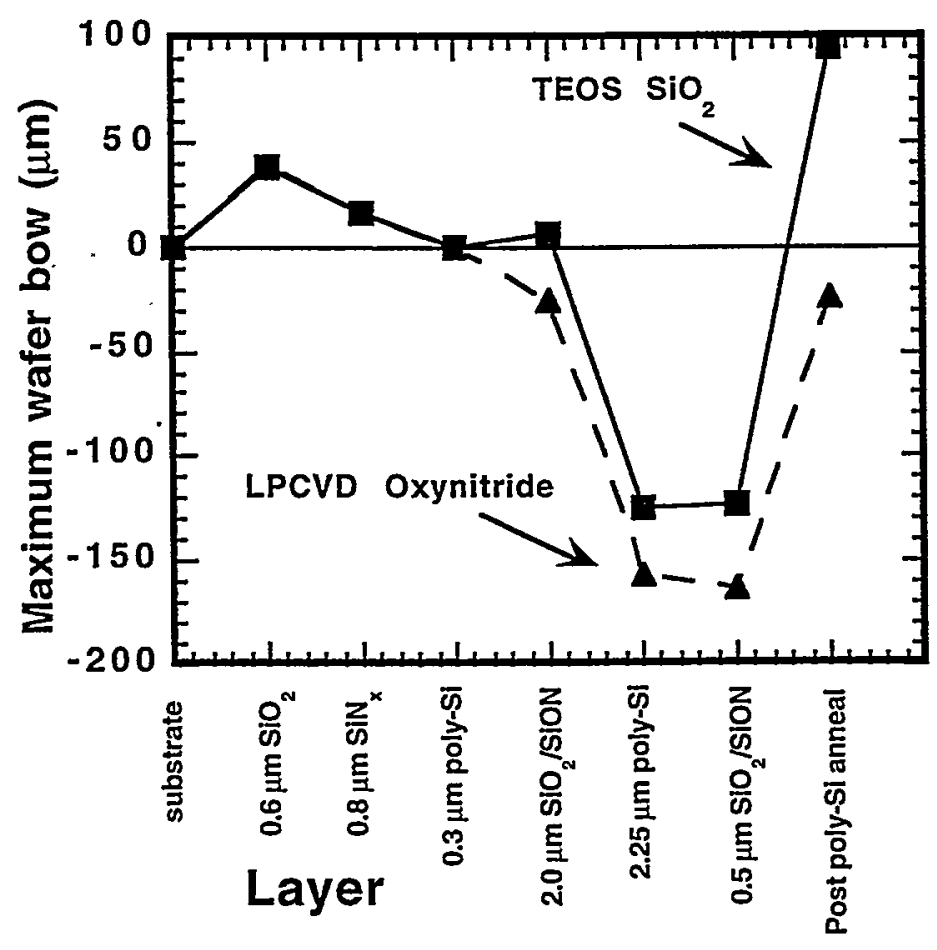

Figure 2. Predicted maximum wafer bow per process step for film stacks produced with either TEOS $\mathrm{SiO}_{2}$ or LPCVD Oxynitride sacrificial layers.

To alleviate the extreme wafer deformation associated with stress evolution of the poly-Si and TEOS $\mathrm{SiO}_{2}$ under anneal, low residual stress oxynitride films are substituted into the film stack as the sacrificial oxide layers. Figure 3 demonstrates the relationship between the residual film stress of $\mathrm{SiO}_{x} \mathrm{~N}_{\mathrm{y}}$ films and the film index of refraction, $\mathrm{n}$. It is observed that films with $\mathrm{n}$ in the range of 1.55 to 1.65 exhibit residual stresses in the range of 0 to $350 \mathrm{MPa}$ and are thermally stable. $\mathrm{SiO}_{\mathrm{x}} \mathrm{N}_{\mathrm{y}}$ films with $\mathrm{n}=1.56$ exhibit a residual stress of approximately $70 \mathrm{MPa}$ asdeposited and less than $10 \mathrm{MPa}$ after anneal at $1100 \mathrm{C}$ for $3 \mathrm{~h}$.

The predicted wafer bow for film stacks with an $n=1.56$ oxynitride sacrificial layer is also shown in fig. 2. The slightly tensile nature of the oxynitride acts in concert with the tensile poly-Si to drive the maximum predicted wafer bow to approximately $-160 \mu \mathrm{m}$. However, after annealing to stress relieve the poly-Si the wafer will flatten significantly to a maximum bow of $-20 \mu \mathrm{m}$.

The predictions of fig. 2 were verified in an experiment where film stacks were prepared with either TEOS $\mathrm{SiO}_{2}$ or oxynitride sacrificial layers. Figure 4 shows the results of the experiment. Film stacks were prepared with films deposited on both sides of the wafer up through the $0.5 \mu \mathrm{m}$ sacrificial oxide and final anneal. At this point the $0.5 \mu \mathrm{m}$ sacrificial oxide 
and the $2.25 \mu \mathrm{m}$ poly-Si film were patterned and etched resulting in a slightly negative wafer bow due to the continuous, compressive $0.5 \mu \mathrm{m} \mathrm{SiO} 2$ layer on the back side.

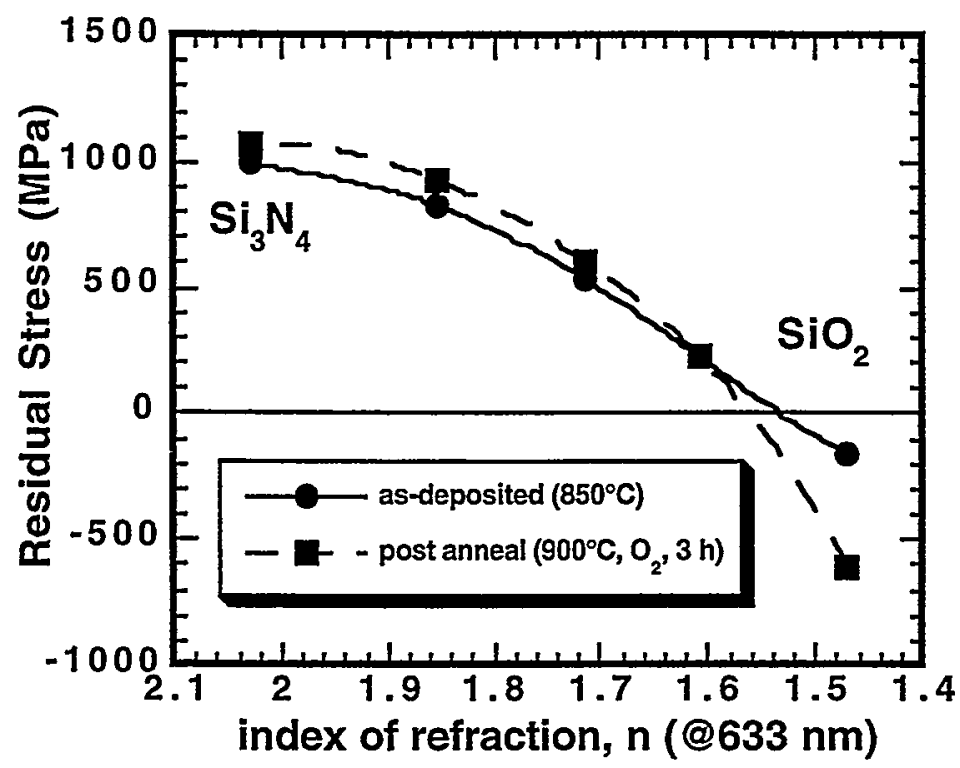

Figure 3. Residual film stress of Si oxynitrides deposited by LPCVD at $850 \mathrm{C}$, and after post deposition anneal at $900 \mathrm{C}$. Similar results are obtained for films deposited at $900 \mathrm{C}$.

The second set of data points in fig. 4 were taken after removing the poly-Si layers and the sacrificial oxides from the wafer backs. For stacks with the TEOS $\mathrm{SiO}_{2}$ sacrificial layers the remaining $2.0 \mu \mathrm{m} \mathrm{SiO} 2$ layer on the wafer front dominates the stress imbalance and drives the wafer to a large positive bow $(45 \mu \mathrm{m})$. For stacks with the oxynitride sacrificial layers the wafer bow becomes slightly more negative $(-20 \mu \mathrm{m})$ since removal of the slightly tensile poly-Si dominates over the essentially zero stress oxynitride.

At the third set of data the remaining $0.8 \mu \mathrm{m}$ low stress nitride and the $0.6 \mu \mathrm{m}$ thermal oxide are removed from the back side. Since these two films are in net compression their removal will tend to increase the wafer bow to more positive values: to $55 \mu \mathrm{m}$ for stacks with $\mathrm{TEOS} \mathrm{SiO}_{2}$, and to $-15 \mu \mathrm{m}$ for stacks with oxynitride sacrificial layers. These results are completely consistent with the predictions of fig. 2 .

Figure 5 shows the deflection for poly-Si cantilevers (anchored to the associated sacrificial material) that have been etch released and dried. For cantilevers formed from poly-Si which utilized TEOS $\mathrm{SiO}_{2}$ sacrificial layers in the process the average radius of curvature is $-460 \pm 105 \mathrm{~mm}$. Cantilevers formed with low stress oxynitride sacrificial layers exhibited a radius of curvature with an average magnitude of $750 \pm 110 \mathrm{~mm}$. These results suggest a reduced stress gradient across the thickness of the poly-Si film when processed with oxynitride sacrificial layers. Additionally, the magnitude of the unloaded beam take-off angle, defined as the initial slope of the beam at the anchor point (i. e., $x=0$ ), is observed to be smaller for cantilevers anchored to the oxynitride than to the TEOS $\mathrm{SiO}_{2}: 0.20 \pm 0.08$ vs. $1.42 \pm 0.16$ microradians, respectively. The comparatively low residual stress of the oxynitride, along with its thermal stability, are considered to be the dominant effect for producing flatter poly-Si beams with reduced take-off angles. To a lesser degree the thermal coefficient of expansion for the 
oxynitride will be more closely matched to poly-Si than $\mathrm{SiO}_{2}$ and may be contributing to the improved results.

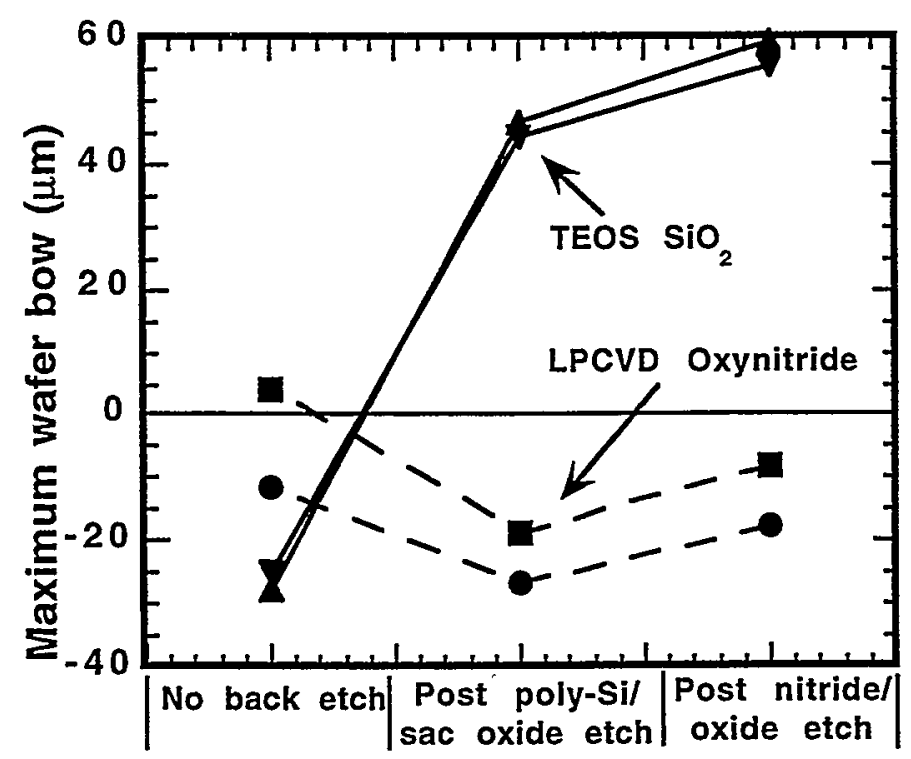

Figure 4. Observed wafer bow for film stack completed through pattern and etch of $0.5 \mu \mathrm{m}$ sacrificial oxide/2.25 $\mu \mathrm{m}$ poly-Si layers, and as back side films are sequentially removed. Results from two wafers of each type are displayed.

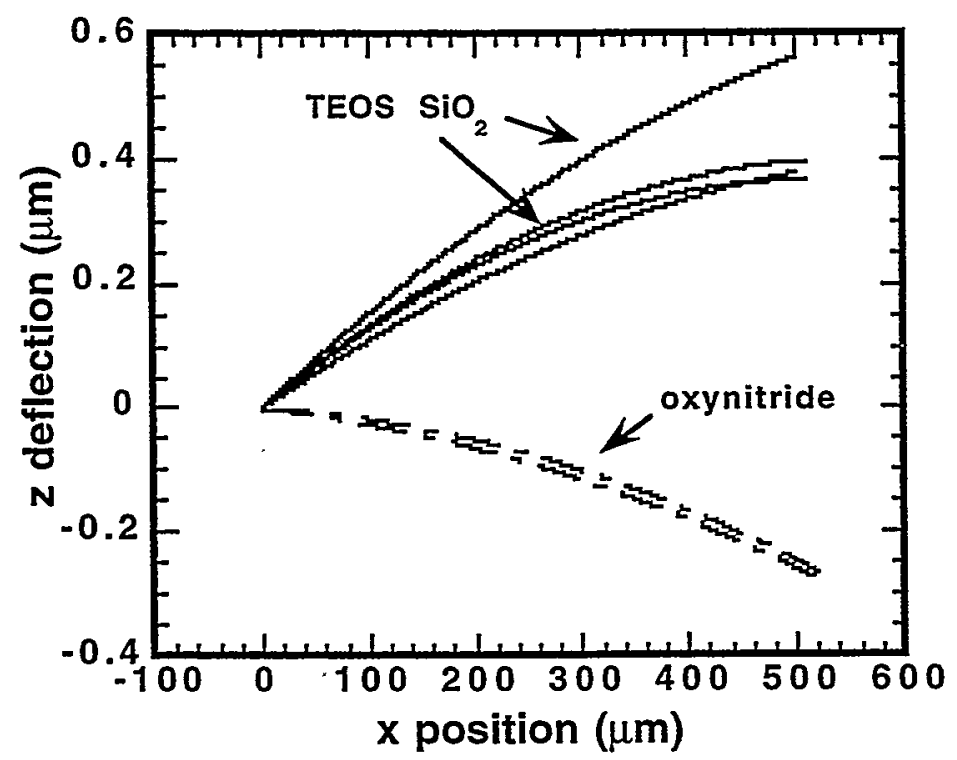

Figure 5. Out of plane deflection of $20 \mu \mathrm{m} \times 475 \mu \mathrm{m}$ poly-Si cantilever beams processed with TEOS $\mathrm{SiO}_{2}$ or LPCVD oxynitride sacrificial layers. 
It is apparent in fig. 5 that the unloaded beam take-off angle for the oxynitrides is negative, compared to a positive angle for the TEOS $\mathrm{SiO}_{2}$ processed cantilevers. This effect has not been investigated in detail, but is believed to be a consequence of how a given anchor material pins the lower surface of the beam. A beam constrained by an anchor material in compression, such as $\mathrm{SiO}_{2}$, will have a tendency to deflect with a positive angle upon release, while a beam constrained by a material in tension will tend to deflect toward negative angles upon release.

\section{CONCLUSION}

To address the issue of wafer deformation in conventional surface micromachining of MEMS, low residual stress silicon oxynitride etch release layers have been investigated as a substitute for $\mathrm{LPCVD} \mathrm{TEOS} \mathrm{SiO}_{2}$. The results indicate that this substitution has the potential for achieving flatter wafers after stress relieving the poly-Si mechanical layers. Additionally, it is observed that etch released poly-Si cantilevers processed with oxynitride release layers exhibit reduced curvature and smaller unloaded beam take-off angles. The low residual stress and good thermal stability of the oxynitride are considered to be the predominant effects that manifest these results.

\section{ACKNOWLEDGEMENTS}

The authors express gratitude to the staff of the Microelectronics Development Laboratory. This work was supported by the United States Department of Energy under Contract DE-AC04-94AL85000. Sandia is a multiprogram laboratory operated by Sandia Corporation, a Lockheed Martin Company, for the United States Department of Energy.

\section{REFERENCES}

1. J. Buhler, F-P Steiner and H. Baltes, J. Micromech. Microeng. 7, p. R1 (1997).

2. H. Guckel, J. J. Sniegowski, T. R. Christenson, S. Mohney and T. F. Kelly, Sensors \& Actuators 20, p.117 (1989).

3. N. S. Saks, D. I. Ma, D. M. Fleetwood, and M. E. Twigg in Proceedings of the ECS Syposium on Silicon Nitride and Silicon Dioxide Thin Insulating Films, edited by V. Kapoor (Electrochemical Society, New York, 1994).

4. S. Habermehl, R. D. Nasby, and M. J. Rightley, Appl. Phys. Lett. 75(8), p.1122 (1999).

5. F. H. P. M. Habraken and A. E. T. Kuiper, Mater. Sci. Eng. R. 12, p. 123 (1994).

6. M. J. Rand and J. F. Roberts, J. Electrochem. Soc. 120(3), p. 446 (1973).

7. S. Limary, H. Stewart, L. Irwin, J. McBrayer, J. J. Sniegowski, S. Montague, J. Smith, M. de Boer, and J. Jakubczak, SPIE Proceedings: Micromachining and Microfabrication Process Technology V 3874, p.102 (1999).

8. S. Habermehl, J. Appl. Phys. 83(9), p. 4672 (1998).

9. See ASTM standards on wafer bow and warp, methods F 534-97 and F 657-92.

10. M. P. de Boer and T. A. Michalske, J. Appl. Phys. 86(2), p. 817 (1999).

11. R. J. Jaccodine and W. A. Schlegel, J. Appl. Phys. 37, p. 2429 (1966).

12. S. Habermehl, (unpublished). 